\title{
RESPIRATORY PARAMETERS AT VARIED ALTITUDES IN INTERMITTENT MINING WORK
}

\author{
ALESSANDRO BACALONI ${ }^{1}$, MARGARITA CECILIA ZAMORA SA $\grave{A}^{2}$, FEDERICA SINIBALDI, \\ ALESSIA STEFFANINA ${ }^{4}$, and SUSANNA INSOGNA ${ }^{1}$ \\ ${ }^{1}$ Sapienza University of Rome, Rome, Italy \\ Department of Chemistry \\ ${ }^{2}$ Catholic University of Santiago, Santiago, Chile \\ Department of Industries (DUOC) \\ ${ }^{3}$ Sapienza University of Rome, Rome, Italy \\ Department of Anatomy, Histology, Medical-Legal and the Orthopaedics, Unit of Occupational Medicine \\ ${ }^{4}$ Sapienza University of Rome, Rome, Italy \\ Laboratory of Respiratory Pathophysiology, Department of Public Health and Infectious Diseases
}

\begin{abstract}
Objectives: Workers in the mining industry in altitude are subjected to several risk factors, e.g., airborne silica and low barometric pressure. The aim of this study has been to assess the risks for this work category, evaluating single risk factors as airborne silica, altitude and work shift, and relating them with cardiovascular and ventilatory parameters. Material and Methods: Healthy miners employed in a mining company, Chile, working at varied altitudes, and subjected to unusual work shifts, were evaluated. Cardiovascular and respiratory parameters were investigated. Exposure to airborne silica was evaluated and compared to currently binding exposure limits. Results: At varied altitudes and work shifts, alterations emerged in haemoglobin, ventilation and respiratory parameters, related to employment duration, due to compensatory mechanisms for hypoxia. Haemoglobin increased with altitude, saturation fell down under $90 \%$ in the highest mines. The multiple linear regression analysis showed a direct relationship, in the higher mine, between years of exposure to altitude and increased forced vital capacity percent ( $\mathrm{FVC} \%)$, and forced expiratory volume in $1 \mathrm{~s}\left(\mathrm{FEV}_{1}\right)$. An inverse relationship emerged between forced vital capacity (FVC) and years of exposure to airborne silica. In the workplace Mina Subterrànea (MT-3600), statistically significant inverse relationship emerged between the Tiffeneau index and body weight. Conclusions: The working conditions in the mining industry in altitude appeared to be potentially pathogenic; further investigations should be realized integrating risk assessment protocols even in consideration of their undeniable unconventionality. Int J Occup Med Environ Health 2018;31(2):129-138
\end{abstract}

Key words:

Shift work, High altitude, Silica, Risk assessment, Mining, Mountain-top mining

Received: July 28, 2016. Accepted: December 4, 2016.

Corresponding author: A. Bacaloni, Sapienza University of Rome, Department of Chemistry, Piazzale Aldo Moro 5, 00185 Rome, Italy (e-mail: alessandro.bacaloni@uniroma1.it). 


\section{INTRODUCTION}

Risk assessment in the mining industry is a challenge for the occupational physician and the industrial hygienist, who need to collaborate in the identification, evaluation and proper management of concurrent risk factors.

Apart from work accidents, maybe the most important risk factor in the mining industry is the exposure to airborne silica. Indeed, the main occupational disease contracted in the mining sector is silicosis, a pneumoconiosis caused by inhaling dust containing free crystalline silica (silicon dioxide) that degenerates in a dose-dependent progressive pulmonary fibrosis. Although silicosis is classified as a chronic restrictive bronchopneumopathy, in the early stages, obstructive airway disease is detectable [1].

The main productive activity in Chile consists in the mining industry, in particular copper mining. Only the state-owned Copper Corporation (Codelco) employs over 40000 people among miners, clerical workers and professional staff.

The working conditions are peculiar. Copper extraction takes place mainly along the Andes Mountains, at altitudes ranging from $1500 \mathrm{~m}$ to more than $4000 \mathrm{~m}$. As atmospheric pressure decreases with increasing altitude, these workplaces are characterized by a rarefied atmosphere. In literature, altitude is generally considered as a risk for workplaces above $3000 \mathrm{~m}$ [2] but several authors observed altitude sickness symptoms yet above $1500 \mathrm{~m}$ [3]. At low barometric pressure, in order to compensate for the low oxygen levels, a progressive time-dependent hyperventilation occurs; the exercise due to the mining work may accentuate the hyperventilation. As larger amounts of air per unit of time are inhaled, more airborne silica, if any, can be inhaled [4,5]. Electrocardiographic changes during exercise in hypoxic conditions were investigated [6] and altered sleep quality and nocturnal apnoeas were observed in Chilean miners working in altitude [7]. In addition, unusual work shifts are logistically required for miners, with schedules consisting of 12 -h shifts, alternating day and night shifts. Unusual work shifts and night shifts are physically, mentally and emotionally stressful; they may cause obesity, diabetes [8,9] and sleep disorders [10]. In previous researches, acclimatization in Chilean mine workers exposed to altitude was investigated, reproducing working conditions through submaximal exercise, but without carefully considering the unusual work shifts $[11,12]$. The aim of this study has been to evaluate the current working conditions in mining industry in altitude and to assess the risks for this work category, evaluating the risk factors airborne silica, altitude and work shift, and relating them with cardiovascular, laboratory and ventilatory parameters.

\section{MATERIAL AND METHODS}

\section{Database processing}

We realized a cross-sectional study. The initial sample consisted of 1627 workers of Codelco Andina, Chile. Personal and job data were collected. Among recorded data: gender; date of birth; date of recruitment; the type of contract (open-ended, fixed-term, externally-funded, consultancy); task; work shift schedule; workplace (Mina Sur, Mina Subterrànea, Saladillo and Planta Filtro).

The following inclusion criteria were considered for sample selection: male workers; age between 20 and 58 years old; assignments with similar metabolic load; no evidence of chronic or acute respiratory, cardiovascular and hematological diseases in the last 30 days; no consequences of chronic respiratory diseases; no polycythemia, hypertension or obesity diagnosis; no obstructive sleep apnoea syndrome diagnosis; less than 10 packs-year smoking history for workers over 45 years.

The final sample consisted of 260 miners working at varied altitudes with the $4 \times 4$ work shift (two 12-h day shifts and two 12-h night shifts, followed by 4 rest days).

This study group was divided according to the workplace: 82 miners from Mina Sur (MS-4300), an open-cut mine located between $3700 \mathrm{~m}$ and $4300 \mathrm{~m} ; 119$ miners 
from Mina Subterrànea (MT-3600), an underground mine located between $3070 \mathrm{~m}$ and $3656 \mathrm{~m}$; 59 miners from Saladillo and Planta Filtro (SPF-1500), mineral comminution plants located between $1535 \mathrm{~m}$ and $1570 \mathrm{~m}$.

The subjects were informed in detail about the experimental procedures prior to the study and they gave their written consents. The experimental protocol was approved by the Accident and Occupational Diseases Safety Board of Codelco (Seguridad Accidentes del Trabajo y Enfermedades Profesionales en Codelco).

\section{Data evaluation}

In order to investigate possible compensation mechanisms and degree of acclimatization, the following parameters were evaluated and related to the altitude of workplaces: hemoglobin saturation, heart rate, respiratory rate, tidal volume, minute volume and spirometric parameters (forced vital capacity - FVC, forced expiratory volume in $1 \mathrm{~s}-\mathrm{FEV}_{1}$, Tiffeneau index $-\mathrm{FEV}_{1} / \mathrm{FVC}$, maximum midexpiratory flow - MMEF75/25).

Clinical measurements were performed within 1 year, excluding austral winter, both at high and moderate altitudes. Measurements at high altitude were realized in the dedicated infirmaries of the selected workplaces (MS-4300, MT-3600 and SPF-1500). Measurements at moderate altitude were realized in the health care facility "Clinica Rio Blanco" located at Los Andes, $800 \mathrm{~m}$ above sea level (LA-800).

Each miner of the study group was examined after, at least, a 10-min pause from any manual work, in 3 different situations: at high altitude during both day and night work shifts, and at moderate altitude during a rest day.

Heart rate and hemoglobin saturation were measured with a pulse oximeter, Fingertip Oximeter, model RMS-50D. Respiratory rate and minute volume were measured with a Wright/Haloscale Respirometer. Spirometric measurements were realized with a Jager Masterscreen Pneumo spirometer. Each parameter was measured in triplicate during the first or the second day of the selected shift.
The overall time required for the complete test varied between $20 \mathrm{~min}$ and $30 \mathrm{~min}$ per subject.

In addition, exposure to airborne crystalline silica was evaluated. Exposure values ranged $0.006-0.175 \mathrm{mg} / \mathrm{m}^{3}$ : several exposures did not respect the threshold limit value - time weighted average (TLV-TWA) $\left(0.025 \mathrm{mg} / \mathrm{m}^{3}\right)$ [13] especially in the underground site. In MT-3600, TLV-TWA was exceeded in 18 out of 37 measurements. In MS-4300, TLV-TWA was exceeded in 1 out of 15 measurements. Besides, the eventual respect of TLV seems to be only formal, in consideration of unusual altitude and work shifts.

In a dedicated work by the same authors, exposure limits corrected for and to be employed at high altitude will be proposed and risk evaluation for contemporary exposition to airborne silica and low barometric pressure (high altitude) will be discussed.

\section{Statistical analysis}

Arithmetic mean and standard deviation for all measured parameters were calculated, and compared by ANOVA test. Results were compared by Wilcoxon and KruskalWallis tests. Shapiro-Wilk test was applied to verify data normality. Finally, data was re-analyzed by means of multiple linear regression methods by using the Tiffenau index and respiratory parameters as dependent variables, and years of exposure to altitude and silica, body weight and age as independent variables. Data was processed with IBM SPSS Advanced Statistics 20.0 software. The sample is described in the Table 1.

\section{RESULTS}

\section{The effect of altitude on hemoglobin}

In order to evaluate the degree of acclimatization of Chilean miners working at varied altitudes, hemoglobin levels were measured and related to altitude. Ninety-nine percent of hemoglobin levels measured in the study group resulted as non-pathological; no evidence of polycythemia emerged. Hemoglobin levels (expressed in $\mathrm{g} / \mathrm{dl}$ ) sorted by 
Table 1. Descriptive analysis of the investigated sample $(\mathrm{N}=260)$ - healthy miners employed in a mining company, Chile, working at varied altitudes, and subjected to unusual work shifts

\begin{tabular}{lrr}
\hline \multicolumn{1}{c}{ Respondents characteristics } & $\mathrm{M} \pm \mathrm{SD}$ & $\mathrm{Me}$ \\
\hline Age [years] & $40.70 \pm 7.600$ & 40.00 \\
Body height [m] & $1.71 \pm 0.050$ & 1.71 \\
Body weight [kg] & $67.50 \pm 4.750$ & 67.00 \\
Respiratory parameters [1] & & \\
$\quad$ tidal volume & $0.54 \pm 0.037$ & 0.54 \\
$\quad$ minute volume & $7.56 \pm 0.520$ & 7.53 \\
Exposure [years] & & \\
$\quad$ to silica & $7.69 \pm 6.570$ & 18.49 \\
$\quad$ to altitude & $8.78 \pm 6.460$ & 18.49 \\
\hline
\end{tabular}

M - mean; SD - standard deviation; Me - median.

workplace (different altitudes) were compared (Figure 1). Hemoglobin increased with altitude, with the highest values at MS-4300 and the lowest values in the mineral comminution plants (SPF-1500).

\section{The effect of altitude on respiratory parameters}

The measured forced vital capacity (FVC) levels appeared to be normal. Forced vital capacity levels (expressed in

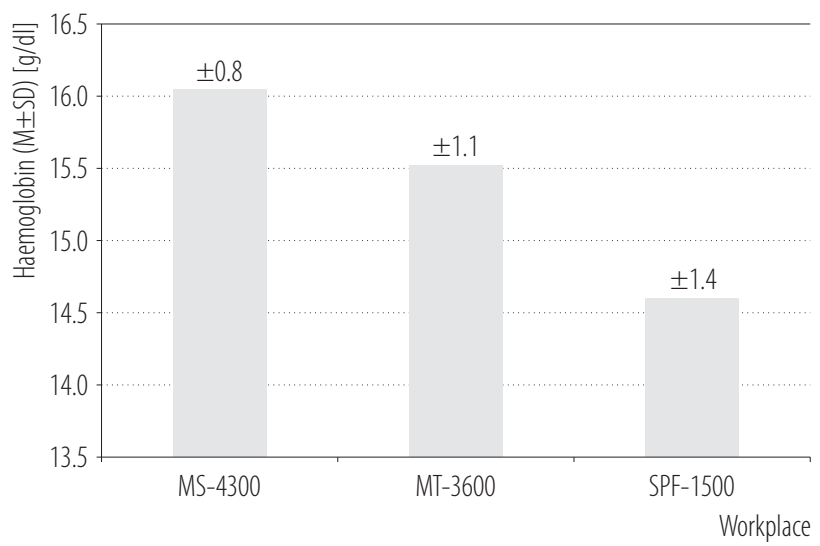

M - mean; SD - standard deviation.

MS-4300 - Mina Sur; MT-3600 - Mina Subterrànea;

SPF-1500 - Saladillo and Planta Filtro.

Fig. 1. Hemoglobin levels in miners $(\mathrm{N}=260)$ employed in a mining company, Chile, by workplace (altitude) terms of percentage share of predicted), respiratory rate levels (expressed in breaths per minute), tidal volume levels (expressed in liters), minute volume levels (expressed in liters) sorted by workplace during day shift, night shift and at rest were compared by ANOVA test according to different work shifts and workplaces, but no significance emerged.

\section{The effect of altitude on heart rate}

Heart rate levels (expressed in beats per minute) sorted by workplace during day and night shifts and at rest were compared according to different work shifts and workplaces (Figure 2). ANOVA test showed, within the groups divided by workplace, significant differences in heart rate variability between work shifts, as reported in the Table 2.

\section{The effect of altitude on hemoglobin saturation}

Hemoglobin oxygen saturation levels $\left(\mathrm{SO}_{2}\right)$ (expressed in terms of percentage share) sorted by workplace were compared according to different work shifts and workplaces (Figure 3). Hemoglobin saturation levels higher than $95 \%$ were observed only at SPF-1500. ANOVA test showed, within the groups divided both by workplace and by work shift, significant differences in $\mathrm{SO}_{2}$ variability between work shifts, as reported in the Tables 3 and 4. 


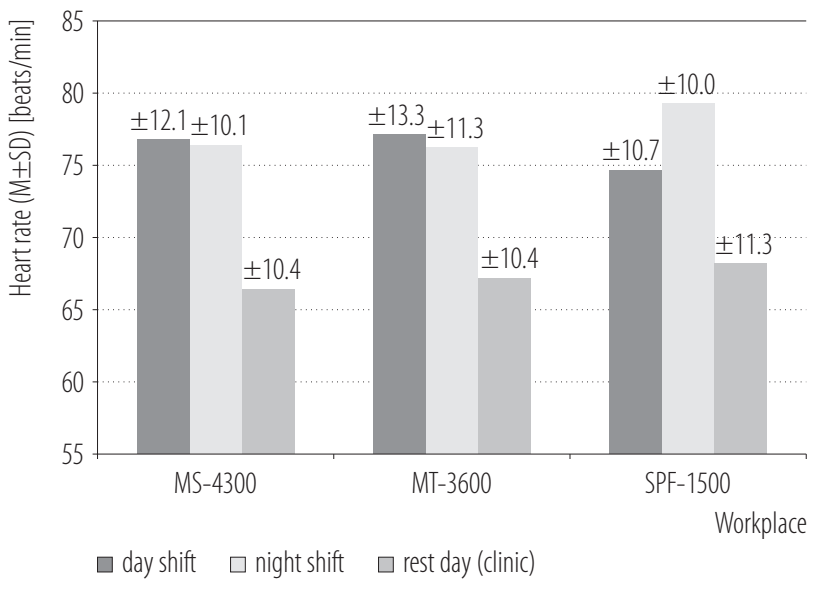

Abbreviations as in Figure 1.

Fig. 2. Heart rate values in miners $(\mathrm{N}=260)$ employed in a mining company, Chile, by work shift and workplace (altitude)

\section{Conformation and analysis of subgroups with varied ventilation in altitude}

In order to identify the main risk factors in the described working conditions, available data was statistically pro-

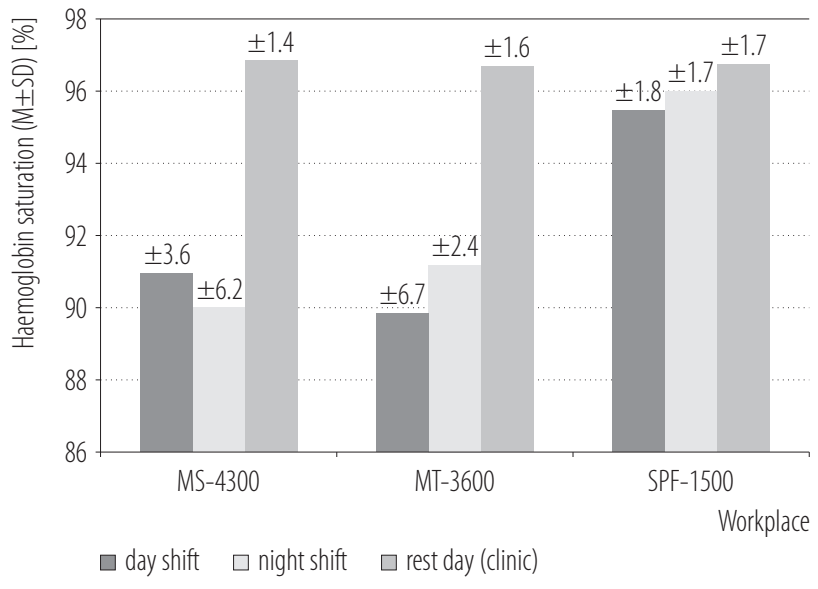

Abbreviations as in Figure 1.

Fig. 3. Haemoglobin saturation in miners $(\mathrm{N}=260)$ employed in a mining company, Chile, by work shift and workplace (altitude)

cessed. The study group stratified by workplace was divided by comparing minute volume at high and moderate altitudes. The subgroup "higher minute volume (HMV)" identified subjects with increased pulmonary ventila-

Table 2. ANOVA test on heart rate values of the miners employed in a mining company, Chile, by workplace and work shift

\begin{tabular}{|c|c|c|c|c|c|c|c|}
\hline \multirow[t]{2}{*}{ Workplace } & \multirow{2}{*}{$\begin{array}{l}\text { Respondents } \\
(\mathrm{N}=260) \\
{[\mathrm{n}]}\end{array}$} & \multicolumn{2}{|c|}{$\begin{array}{l}\text { Heart rate } \\
\text { [beats/min] }\end{array}$} & \multirow{2}{*}{$\mathrm{df}_{\text {between }}$} & \multirow{2}{*}{$\mathrm{df}_{\text {within }}$} & \multirow[t]{2}{*}{$\mathrm{F}$} & \multirow[t]{2}{*}{$\mathrm{p}$} \\
\hline & & $\mathrm{M}$ & variance & & & & \\
\hline MS-4300 & 82 & & & 2 & 221 & 3.03 & 0.000 \\
\hline day shift & & 76.80 & 145.60 & & & & \\
\hline night shift & & 76.46 & 101.50 & & & & \\
\hline rest day (clinic) & & 66.41 & 108.22 & & & & \\
\hline MT-3600 & 119 & & & 2 & 306 & 3.02 & 0.000 \\
\hline day shift & & 77.09 & 176.62 & & & & \\
\hline night shift & & 76.23 & 128.01 & & & & \\
\hline rest day (clinic) & & 67.17 & 108.76 & & & & \\
\hline SPF-1500 & 59 & & & 2 & 106 & 3.08 & 0.0006 \\
\hline day shift & & 74.65 & 113.92 & & & & \\
\hline night shift & & 79.29 & 99.97 & & & & \\
\hline rest day (clinic) & & 68.20 & 127.40 & & & & \\
\hline
\end{tabular}

MS-4300 - Mina Sur; MT-3600 - Mina Subterrànea; SPF-1500 - Saladillo and Planta Filtro.

$\mathrm{M}$ - mean; df - degrees of freedom, between or within group; F - F statistic. 
Table 3. ANOVA test on hemoglobin saturation values of the miners employed in a mining company, Chile, by workplace

\begin{tabular}{|c|c|c|c|c|c|c|c|}
\hline \multirow[t]{2}{*}{ Workplace } & \multirow{2}{*}{$\begin{array}{c}\text { Respondents } \\
(\mathrm{N}=260) \\
{[\mathrm{n}]}\end{array}$} & \multicolumn{2}{|c|}{$\begin{array}{c}\text { Hemoglobin saturation } \\
{[\%]}\end{array}$} & \multirow[t]{2}{*}{$\mathrm{df}_{\text {between }}$} & \multirow[t]{2}{*}{$\mathrm{df}_{\text {within }}$} & \multirow[t]{2}{*}{$\mathrm{F}$} & \multirow[t]{2}{*}{$\mathrm{p}$} \\
\hline & & M & variance & & & & \\
\hline MS-4300 & 82 & & & 2 & 221 & 3.03 & 0.000 \\
\hline day shift & & 90.95 & 12.84 & & & & \\
\hline night shift & & 90.01 & 38.19 & & & & \\
\hline rest day (clinic) & & 96.84 & 2.05 & & & & \\
\hline MT-3600 & 119 & & & 2 & 306 & 3.02 & 0.000 \\
\hline day shift & & 89.84 & 44.17 & & & & \\
\hline night shift & & 91.18 & 5.88 & & & & \\
\hline rest day (clinic) & & 96.69 & 2.51 & & & & \\
\hline SPF-1500 & 59 & & & 2 & 106 & 3.08 & 0.003 \\
\hline day shift & & 95.48 & 3.32 & & & & \\
\hline night shift & & 96.00 & 2.75 & & & & \\
\hline rest day (clinic) & & 96.74 & 2.82 & & & & \\
\hline
\end{tabular}

Abbreviations as in Table 2.

Table 4. ANOVA test on hemoglobin saturation values of the miners employed in a mining company, Chile, by work shift

\begin{tabular}{|c|c|c|c|c|c|c|c|}
\hline \multirow{2}{*}{$\begin{array}{c}\text { Work shift } \\
\text { and workplace }\end{array}$} & \multirow{2}{*}{$\begin{array}{c}\text { Respondents } \\
(\mathrm{N}=260) \\
{[\mathrm{n}]}\end{array}$} & \multicolumn{2}{|c|}{$\begin{array}{c}\text { Hemoglobin saturation } \\
{[\%]}\end{array}$} & \multirow{2}{*}{$\mathrm{df}_{\text {between }}$} & \multirow{2}{*}{$\mathrm{df}_{\text {within }}$} & \multirow[t]{2}{*}{ F } & \multirow{2}{*}{$\mathrm{p}$} \\
\hline & & $\mathrm{M}$ & variance & & & & \\
\hline Day shift & 260 & & & 2 & 238 & 3.03 & 0.000 \\
\hline MS-4300 & & 90.95 & 12.84 & & & & \\
\hline MT-3600 & & 89.84 & 44.17 & & & & \\
\hline SPF-1500 & & 95.48 & 3.32 & & & & \\
\hline Night shift & 260 & & & 2 & 168 & 3.05 & 0.000 \\
\hline MS-4300 & & 90.01 & 38.19 & & & & \\
\hline MT-3600 & & 91.18 & 5.88 & & & & \\
\hline SPF-1500 & & 96.00 & 2.75 & & & & \\
\hline Rest day (clinic) & 260 & & & 2 & 227 & 3.04 & 0.81 \\
\hline MS-4300 & & 96.84 & 2.05 & & & & \\
\hline MT-3600 & & 96.69 & 2.51 & & & & \\
\hline SPF-1500 & & 96.74 & 2.82 & & & & \\
\hline
\end{tabular}

Abbreviations as in Table 2.

tion at high altitude; the subgroup "lower minute volume (LMV)" identified subjects with reduced pulmonary ventilation at high altitude. Average years of exposure to altitude, minute volume, heart rate and hemoglobin saturation in the identified subgroups are described in the Table 5 .

In the subgroup with increased ventilation at high altitude, average minute volume increased by $14 \%$ at $1500 \mathrm{~m}$ and 
Table 5. Characteristics of miners $(\mathrm{N}=260)$, employed in a mining company, Chile, with different ventilation in altitude

\begin{tabular}{|c|c|c|c|c|c|c|}
\hline \multirow{2}{*}{ Characteristics } & \multicolumn{2}{|c|}{ MS-4300 } & \multicolumn{2}{|c|}{ MT-3600 } & \multicolumn{2}{|c|}{ SPF-1500 } \\
\hline & HMV & LMV & HMV & LMV & HMV & LMV \\
\hline Respondents [\%] & 52.0 & 48.0 & 51.0 & 49.0 & 50.0 & 50.0 \\
\hline Age [years] & 40.1 & 41.1 & 40.9 & 39.5 & 42.0 & 42.0 \\
\hline Exposure to altitude [years] & 10.3 & 8.4 & 10.3 & 8.6 & 5.7 & 5.9 \\
\hline \multicolumn{7}{|l|}{ Minute volume [1] } \\
\hline day shift & 13.8 & 11.6 & 15.0 & 12.2 & 13.0 & 12.8 \\
\hline night shift & 14.3 & 12.5 & 14.5 & 12.7 & 12.1 & 14.0 \\
\hline rest day (clinic) & 11.7 & 14.5 & 12.3 & 15.0 & 11.0 & 16.7 \\
\hline \multicolumn{7}{|l|}{ Heart rate [beats/min] } \\
\hline day shift & 78.7 & 75.0 & 80.2 & 72.9 & 75.7 & 75.2 \\
\hline night shift & 78.4 & 75.7 & 76.5 & 75.8 & 72.4 & 85.3 \\
\hline rest day (clinic) & 67.0 & 65.8 & 65.3 & 69.1 & 65.8 & 71.2 \\
\hline \multicolumn{7}{|l|}{ Hemoglobin saturation [\%] } \\
\hline day shift & 91.7 & 90.0 & 91.3 & 89.8 & 95.8 & 94.9 \\
\hline night shift & 90.2 & 89.6 & 91.7 & 90.9 & 95.6 & 96.6 \\
\hline rest day (clinic) & 97.0 & 96.7 & 96.9 & 96.5 & 96.8 & 96.6 \\
\hline \multicolumn{7}{|l|}{$\begin{array}{l}\text { Respondents with hemoglobin } \\
\text { saturation }<90 \%[\mathrm{n}]\end{array}$} \\
\hline day shift & 11 & 18 & 10 & 14 & 0 & 1 \\
\hline night shift & 11 & 11 & 4 & 8 & 0 & 0 \\
\hline rest day (clinic) & 0 & 0 & 0 & 0 & 0 & 0 \\
\hline
\end{tabular}

HMV - higher minute volume at different altitudes; LMV - lower minute volume at different altitudes.

Other abbreviations as in Table 2.

by $20 \%$ above $3000 \mathrm{~m}$, compared to minute volume levels recorded at $800 \mathrm{~m}$.

In the highest workplace, MS-4300, hemoglobin saturation was below $90 \%$ for $28 \%$ of HMV subjects and for $50 \%$ (day shift), and 30\% (night shift) of LMV subjects. In the underground mine, MT-3600, hemoglobin saturation was below $90 \%$ for $18 \%$ (day shift) and $7 \%$ (night shift) of HMV subjects and for 26\% (day shift) and 15\% (night shift) of LMV subjects.

Relationship between respiratory parameters and years of exposure to altitude, and airborne silica.

A multiple linear regression analysis was carried out, in which the respiratory parameters composed the dependent variables and years of exposure to altitude and airborne crystalline silica composed the independent variables. Statistically significant results are presented in the Table 6 .

A direct relationship emerged, in the higher mine, between years of exposure to altitude and increased $\mathrm{FVC} \%$, and $\mathrm{FEV}_{1}$. An inverse relationship emerged between FVC and years of exposure to airborne silica.

\section{Relationship between Tiffeneau index and age, and body weight}

A multiple linear regression analysis was carried out, in which the Tiffeneau index composed the dependent variable and age and body weight composed the independent 
Table 6. Relationship between respiratory parameters and years of exposure to altitude, and airborne silica in study of miners $(\mathrm{N}=260)$ employed in a mining company, Chile

\begin{tabular}{|c|c|c|c|c|c|c|c|c|c|}
\hline \multirow{2}{*}{ Exposure } & \multicolumn{3}{|c|}{ MS-4300 } & \multicolumn{3}{|c|}{ MT-3600 } & \multicolumn{3}{|c|}{ SPF-1500 } \\
\hline & $\beta$ & $\mathrm{t}$ & $\mathrm{p}$ & $\beta$ & $\mathrm{t}$ & $\mathrm{p}$ & $\beta$ & $\mathrm{t}$ & $\mathrm{p}$ \\
\hline \multicolumn{10}{|l|}{ Altitude } \\
\hline $\mathrm{FEV}_{1} / \mathrm{FVC}$ & -0.044 & -0.214 & 0.832 & 0.103 & 0.405 & 0.687 & 0.475 & 0.273 & 0.796 \\
\hline FVC & 0.197 & 0.923 & 0.361 & 0.478 & 1.958 & 0.054 & 2.779 & 2.612 & 0.083 \\
\hline $\mathrm{FEV}_{1}$ & 0.580 & 3.109 & 0.003 & 0.374 & 1.506 & 0.136 & 2.894 & 2.673 & 0.044 \\
\hline $\mathrm{FVC} \%$ & 0.588 & 2.997 & 0.004 & 0.286 & 1.181 & 0.241 & 2.267 & 1.620 & 0.166 \\
\hline \multicolumn{10}{|l|}{ Silica } \\
\hline $\mathrm{FEV}_{1} / \mathrm{FVC}$ & 0.362 & 1.759 & 0.085 & -0.011 & -0.043 & 0.966 & -0.254 & -0.146 & 0.890 \\
\hline FVC & -0.315 & -1.477 & 0.146 & -0.643 & -2.635 & 0.010 & -2.627 & -2.044 & 0.096 \\
\hline $\mathrm{FEV}_{1}$ & -0.087 & -0.468 & 0.642 & -0.146 & -0.587 & 0.559 & -2.466 & -2.277 & 0.072 \\
\hline $\mathrm{FVC} \%$ & -0.243 & -1.241 & 0.221 & 0.047 & 0.195 & 0.846 & -1.932 & -1.380 & 0.226 \\
\hline
\end{tabular}

$\mathrm{FEV}_{1} / \mathrm{FVC}$ - Tiffeneau index; $\mathrm{FVC}$ - forced vital capacity; $\mathrm{FEV}_{1}$ - forced expiratory volume in $1 \mathrm{~s} ; \mathrm{FVC} \%$ - forced vital capacity percent. $\beta$ - regression coefficient.

Other abbreviations as in Table 2.

variables. In the workplace MT-3600, statistically significant inverse relationship emerged between the Tiffeneau index and body weight $(\beta=-0.296, \mathrm{t}=-2.616, \mathrm{p}=0.011)$.

\section{DISCUSSION}

According to collected data, hemoglobin values increased with altitude as a consequence of oxygen saturation decreasing. Above $3000 \mathrm{~m}$ (MS-4300 and MT-3600), higher percentage shares of low hemoglobin saturation were recorded among miners with reduced pulmonary ventilation at high altitude, both during day and night shift. It is well known that when hemoglobin saturation falls below $90 \%$, oxygen delivery to tissue, including vital organs, is likely to be inadequate in healthy adults. Without adaptation mechanisms to hypoxia, diseases as acute mountain sickness (AMS), high-altitude pulmonary edema (HAPE), high-altitude cerebral edema (HACE) or, chronic mountain sickness (CMS) may occur [14].

Since data was not available yet, the effect of altitude on blood count was not evaluated. Further investigations will be realized to study the afore mentioned relationship, evaluating the presence of eventual polycythemia and compensation mechanisms to hypoxia, by means of a complete blood count and blood-gas analysis at the end of the shift to examine desaturation in detail.

By analyzing respiratory parameters, interesting alterations emerged.

Average minute volume values measured in Chilean miners ranged from 11.61 to 16.71 of air, levels quite higher than the normal minute ventilation values for healthy subjects at rest, from 61 up to 91 [15] probably due to acclimatization to high altitude and tidal volume and respiratory rate values resulted as altered but no statistically significant differences emerged between groups.

Minute volume values being equal, elevated respiratory rates increase energy demand and consumption by respiratory muscles, with consequent fatigue and labored (fast and shallow) breathing, lower alveolar ventilation and lower saturation [16], as emerged from our results. This physiological process is exacerbated by altitude and work 
load, during both night and day shifts, while at rest $\mathrm{SO}_{2}$ resulted normal. Moreover, as hemoglobin oxygen saturation levels fell below $90 \%$, especially at higher altitude levels during both day and night work shifts, it would be appropriate to consider whether to provide workers with an oxygen support during the work shifts. It would be an interesting object of study, to develop a strategy to provide oxygen support without interfere with physical activity, possibly with oxygen conditioning.

Another significant finding emerged from our study: the relationship ventilator compensation/silica exposure time. In result of the multiple linear regression analysis, direct relationship emerged between length of exposure and $\mathrm{FEV}_{1}$, and FVC, on the other hand, negative correlation emerged between FVC and years of exposure to airborne silica.

Physiologically, the decreased pressure of inspired oxygen is compensated, but toxicological implications emerge. In workplaces characterized by poor air quality, increasing pulmonary ventilation involves larger amount of polluted air to be inhaled and, in particular, larger amount of airborne silica to be inhaled. Thus, at high altitude, higher doses of airborne crystalline silica may be assumed.

In addition, the current TLV levels for silica-containing dusts do not take into account any pulmonary ventilation normalization, therefore they are inadequate to protect exposed workers. A customized algorithm should be compiled.

Finally, we investigated the effects of shift work, and especially night work. We focused on major effects suggested by literature, i.e., the metabolic and respiratory ones $[8,17,18]$. Thus, the relationship between the index of chronic obstructive pulmonary disease (the Tiffenau index) and body weight was studied. Several risk factors, related to obesity and metabolic disorders, may be identified for the investigated job category: shift work and night shifts with irregular shifts [8] and alterations in lung function [17,18]. In Tables 3 and 4, it may be observed that in the highest mine, the lowest oxygen saturation levels occurred during the night shift. It is well known that altitude may affect sleep quality and altitude exposure may exacerbate obstructive sleep apnoea syndrome [11], but the decrease in $\mathrm{SO}_{2}$ during the night shift deserves further investigation. Probably, it may be attributable to an increased metabolic request due to both altitude and the shift performed during the night, that requires more energy [11]. Unfortunately, we did not have the possibility to perform polysomnography, deepening the study of obstructive lung damage due to exposure to unusual shift. In addition, eventual metabolic alterations may be combined to other changes in the cardiovascular system due to altitude [19]; as a result, further studies are needed.

This study is a preliminary research: the first approach focused mainly on respiratory parameters, further studies will include hematological parameters (e.g., blood count or arterial blood gas analysis) in order to evaluate alterations and compensation mechanisms.

\section{CONCLUSIONS}

The working conditions in the mining industry in altitude have appeared to be potentially pathogenic. Acclimatization and compensation mechanisms observed, with increased pulmonary ventilation, imply increased airborne silica inhaling. In order to prevent silica relate diseases, further investigations should be realized to integrate and correct risk assessment protocols.

\section{REFERENCES}

1. Leung CC, Yu IT, Chen W. Silicosis. Lancet. 2012;379(9830): 2008-18, https://doi.org/10.1016/S0140-6736(12)60235-9.

2. Chiodi H. Respiratory adaptations to chronic high altitude hypoxia. J Appl Physiol. 1957;10:81-7.

3. Lumbreras LG, León Velarde F. [The environment in the Andes]. In: Monge CC, León-Velarde F, editors. [The physiological challenge of living in the Andes]. Lima: Institut Français d'Études Andines; Peruvian University Cayetano Heredia; 2003. p. 29-39. Spanish. 
4. Dempsey JA, Powell FL, Bisgard GE, Blain GM, Poulin MJ, Smith CA. Role of chemoreception in cardiorespiratory acclimatization to, and deacclimatization from, hypoxia. J Appl Physiol. 2014;116(7):858-66, https://doi.org/10.1152/ japplphysiol.01126.2013.

5. Dempsey JA, Forster HV, Birnbaum ML, Reddan WG, Thoden J, Grover RF, et al. Control of exercise hyperpnea under varying durations of exposure to moderate hypoxia. Respir Physiol. 1972;16:213-31, https://doi.org/10.1016/00 34-5687(72)90052-7.

6. Coustet B, Lhuissier FJ, Vincent R, Richalet JP. Electrocardiographic changes during exercise in acute hypoxia and susceptibility to severe high-altitude illnesses. Circulation. 2015;131(9):786-94, https://doi.org/10.1161/CIRCULATIO NAHA.114.013144.

7. Moraga FA, Jiménez D, Richalet JP, Vargas M, Osorio P. Periodic breathing and oxygen supplementation in Chilean miners at high altitude (4200 m). Respir Physiol Neurobiol. 2014;203:109-15, https://doi.org/10.1016/j.resp.2014.09.001.

8. Poulsen K, Cleal B, Clausen T, Andersen LL. Work, diabetes and obesity: A seven year follow-up study among Danish health care workers. PLoS One. 2014;9(7):e103425, https:// doi.org/10.1371/journal.pone.0103425.

9. Kanikowska D, Sato M, Witowski J. Contribution of daily and seasonal biorhythms to obesity in humans. Int J Biometeorol. 2015;59(4):377-84, https://doi.org/10.1007/s00484014-0871-z.

10. Yazdi Z, Sadeghniiat-Haghighi K, Loukzadeh Z, Elmizadeh K, Abbasi M. Prevalence of sleep disorders and their impacts on occupational performance: A comparison between shift workers and nonshift workers. Sleep Disord. 2014;2014:870320, https://doi.org/10.1155/2014/870320.
11. Farias JC, Osorio J, Soto G, Brito J, Siques P, Reyes JG. Sustained acclimatization in Chilean mine workers subjected to chronic intermittent hypoxia. High Alt Med Biol. 2006;7(4):302-6, https://doi.org/10.1089/ham.2006.7.302.

12. Richalet JP, Donoso MV, Jiménez D, Antezana AM, Hudson $\mathrm{C}$, Cortès $\mathrm{G}$, et al. Chilean miners commuting from sea level to 4500 m: A prospective study. High Alt Med Biol. 2002; 3(2):159-66, https://doi.org/10.1089/15270290260131894.

13. American Conference of Governmental Industrial Hygienists (ACGIH). Threshold limit values and biological exposure indices. Cincinnati: The Conference; 2014.

14. Luo Y, Wang Y, Lu H, Gao Y. 'Ome' on the range: Update on high-altitude acclimatization/adaptation and disease. Mol Biosyst. 2014;10(11):2748-55, https://doi.org/10.1039/ C4MB00119B.

15. Blackie SP, Fairbarn MS, McElvaney NG, Wilcox PG, Morrison NJ, Pardy RL. Normal values and ranges for ventilation and breathing pattern at maximal exercise. Chest. 1991;100(1):136-42, https://doi.org/10.1378/chest.100.1.136.

16. Gunther B, Diaz G. [Physiology of systems: Breathing]. Santiago: Chilean University; 1977. Spanish.

17. Delgado D, de los Angeles Aguilera M, Delgado F, Rug A. The experience of miners relocated to alternative positions due to silicosis in the Andean of CODELCO, Chile, 2010. Saf Health Work. 2012;3(2):140-5, https://doi.org/10.5491/ SHAW.2012.3.2.140.

18. Littleton SW. Impact of obesity on respiratory function. Respirology. 2012;17(1):43-9, https://doi.org/10.1111/j.14401843.2011.02096.x

19. Whayne TF Jr. Cardiovascular medicine at high altitude. Angiology. 2014;65(6):459-72, https://doi.org/10.1177/0003 319713497086.

This work is available in Open Access model and licensed under a Creative Commons Attribution-NonCommercial 3.0 Poland License - http://creativecommons.org/ licenses/by-nc/3.0/pl/deed.en. 